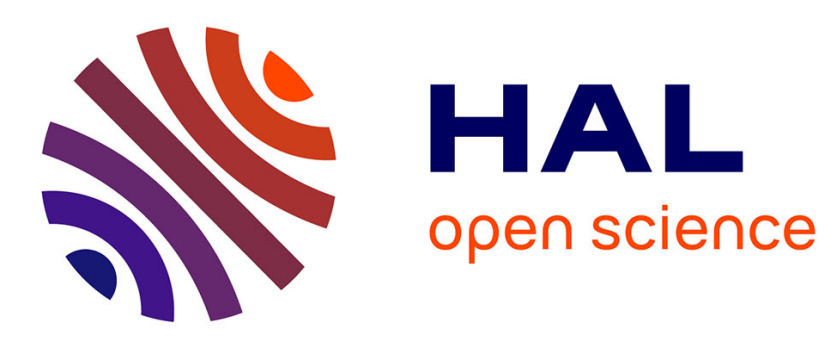

\title{
Interaction between adipose tissue and cancer cells: role for cancer progression
}

Jean-François Dumas, Lucie Brisson

\section{To cite this version:}

Jean-François Dumas, Lucie Brisson. Interaction between adipose tissue and cancer cells: role for cancer progression. Cancer and Metastasis Reviews, 2020, 10.1007/s10555-020-09934-2 . hal-03010632

\section{HAL Id: hal-03010632 \\ https://hal.science/hal-03010632}

Submitted on 17 Nov 2020

HAL is a multi-disciplinary open access archive for the deposit and dissemination of scientific research documents, whether they are published or not. The documents may come from teaching and research institutions in France or abroad, or from public or private research centers.
L'archive ouverte pluridisciplinaire HAL, est destinée au dépôt et à la diffusion de documents scientifiques de niveau recherche, publiés ou non, émanant des établissements d'enseignement et de recherche français ou étrangers, des laboratoires publics ou privés. 
INTERACTION BETWEEN ADIPOSE TISSUE AND CANCER CELLS: ROLE FOR CANCER PROGRESSION

Jean-François Dumas ${ }^{1}$, Lucie Brisson ${ }^{1 *}$

${ }^{1}$ Inserm UMR1069, Nutrition, Growth and Cancer, University of Tours, Tours, France *corresponding author :

Lucie Brisson

Inserm UMR1069 Nutrition, Croissance et Cancer

Université de Tours,

10 boulevard Tonnellé, 37032 Tours, France

Tel 00332473662 83, Email lucie.brisson@inserm.fr 
Abbreviations

AMPK: AMP-activated protein kinase

ATP: adenosine tri phosphate

COX-2: cyclooxygenase-2

CPT1: carnitine palmitoyltransferase I

EMT: epithelial to mesenchymal transition

FABP: fatty acid binding protein

FATP1: fatty acid transport protein 1

GDF: 15 Growth Differentiation Factor 15

HIF-1: hypoxia inducible transcription factor

IGFBP-2: insulin-like growth factor binding protein-2

IL-6: interleukin 6

JAK: Janus kinase

JNK: c-Jun N-terminal kinase

LD: lipid droplets

MCP-1: macrophage chemoattractant protein

MMP: matrix metalloproteinase

NK: natural killer

PGE2: prostaglandin E2

PLOD2: Procollagen-Lysine,2-Oxoglutarate 5-Dioxygenase 2

PPAR: peroxisome proliferator-activated receptors

ROS: reactive oxygen species

STAT: signal transducer and activator of transcription

TGF $\beta$ : Transforming growth factor beta

UCP: uncoupling protein

VHL: von Hippel-Lindau 


\section{$\underline{\text { Abstract }}$}

Environment surrounding tumours are now recognised to play an important role in tumour development and progression. Among the cells found in the tumour environment, adipocytes from adipose tissue establish a vicious cycle with cancer cells to promote cancer survival, proliferation, metastasis and treatment resistance. This cycle is particularly of interest in the context of obesity which has been found as cancer risk factor. Cancers cells can reprogram adipocyte physiology leading to an "activated" phenotype characterized by delipidation and secretion of inflammatory adipokines. The adipocyte secretions then influence tumour growth and metastasis which has been mainly attributed to interleukin 6 (IL-6) or leptin but also to the release of fatty acids which are able to change cancer cell metabolism and signalling pathways. The aim of this review is to report recent advances in the understanding of the molecular mechanisms linking adipose tissue with cancer progression in order to propose new therapeutic strategies based on pharmacological or nutritional intervention.

Key words: adipocyte, cancer, adipokines, metabolism, fatty acid, exosome 
$\underline{\text { Declarations }}$

\section{Funding}

The work performed at the Université de Tours-Inserm UMR1069 was funded by the Inserm, the "Ligue Nationale Contre le Cancer - Inter-région Grand-Ouest", the "Fondation ARC" and the "Cancéropole Grand-Ouest".

\section{Conflicts of interest/Competing interests}

Authors declare no conflict of interest. 
Tumours are complex tissues composed of cancer and non-cancer cells in a hypoxic and nutrient-deprived microenvironment. In order to survive tumour cells need to adapt to these harsh conditions. One main property of cancer cells is their capacity to reprogram metabolism and take advantage of substrates available in the surrounding microenvironment [1]. Several types of cooperation have been demonstrated between cancer and non-cancer cells of the tumour such as macrophages or fibroblasts [2]. Recently the interaction of tumours with the surrounding adipose tissue has gain interest. Indeed tumours, locally or during metastatic dissemination, related closely with adipose tissue. In particular, from the first steps of cancer initiation, mammary tumours are in contact with the adipose tissue of the mammary gland, whereas several other cancers (prostate, ovarian, lung...) interact with the subcutaneous or visceral adipose tissue or with the adipocytes from bone marrow in advanced stages when tumours grown outside of the primary site.

Adipose tissue is the largest energy storage in the body. The majority of adult adipose tissue in humans is the white adipose tissue, composed mainly of white adipocytes, which by a high plasticity allows adapting the storage or the release of fatty acids according to the nutritional status. White adipose tissue is mainly separated into subcutaneous adipose tissue and visceral adipose tissue with heterogeneity in composition and structure [3]. Brown adipose tissue, a minority in humans, is specialized in thermogenesis. Unlike white adipocytes, brown adipocytes contain several small lipid droplets and mitochondria with a high expression of the uncoupling protein UCP1. Adipose tissue is not only a quiescent tissue for the storage of fatty acids but has metabolic and endocrine functions with the secretion of lipid or protein factors named adipokines (hormones, cytokines, growth factors, matrix remodelling components) with endocrine and paracrine functions [4, 5]. Recent studies highlighted the bidirectional interactions, based on adipokines and lipids, between white adipose tissue and tumours and their role on cancer progression (later "adipose tissue" will refer to white adipose tissue). In addition, adipocyte secreted factors have been shown to regulate the expression of genes associated with cancer progression (adhesion, invasion, angiogenesis, signal transduction and apoptosis) in non-cancerous mammary cells suggesting a role in cancer initiation [6].

Fatty acids are now recognised as important actors of cancer cell metabolic reprogramming. Cancer cells fulfil their lipid requirements by de novo synthesis and by the uptake of free fatty acids and lipoproteins from the extracellular microenvironment. Fatty acid synthesis is upregulated in several cancers which has been associated with tumour progression and 
metastasis (for review [7]. In the last decades, it has been demonstrated that besides this increase in fatty acid synthesis, cancer cells develop mechanisms to uptake lipids from the surrounding environment and this may depends on the proximity with the adipose tissue. However, the precise role of fatty acids in tumours is not completely elucidated. Since fatty acids have a high diversity in length and unsaturation, not only the proximity of adipose tissue but also its composition can have important role on cancer progression. Interestingly the lipid composition of adipose tissue correlates with dietary intakes. It has been estimated that 30-35\% of cancerrelated deaths are linked with diet and 14-20\% with obesity [8]. Adipose tissue is deeply remodelled by obesity which is characterized by excessive accumulation of lipids in adipocytes and high secretion of proinflammatory adipokines such as IL-6 or TNF- $\alpha$ [9].

This review aims to describe current knowledge in the cooperation between adipose tissue and cancer cells. The role of adipokines and lipids in these interactions will be discussed with a focus on the role of specific lipids. In this review, we will report studies using conditioned medium and co-culture system to represent the interactions between adipose tissue and cancer cells. The systemic effects of some adipokines independently of the proximity of adipocytes have been reviewed previously $[10,11]$.

1) Modification of adipose tissue by cancer cells : cancer-associated adipocytes

Adipose tissue is highly regulated by environmental factors. Among these factors, it has been demonstrated that tumour secreted factors influence adipocytes leading to an activated phenotype called cancer-associated adipocytes (Fig1). Cancer-associated adipocytes are characterized by a specific phenotype with high lipolysis and overexpression of proteases and proinflammatory cytokines $[12,13]$. These adipocytes are part of a vicious circle where cancer cells induce the secretion of lipids and adipokines by adipocytes to promote tumour growth (see later for the effects of adipocytes on cancer cells). The demonstration of adipose tissue modifications by tumours has been made initially in breast [12] and ovarian [13] cancers but the molecular mechanisms have been demonstrated in several other tumour types such as prostate [14] , pancreas [15], lung [16], hepatocarcinoma [17] and leukaemia [18]. It has been demonstrated in mammary adipose tissue that cancer proximity decreases adipogenesis-related genes and increases the expression of secretion-related genes [12, 19]. Furthermore fat browning proteins like UCP1 have been observed in breast adipose tissue from cancer patients [19]. Altogether these changes promote metabolic remodelling in adipocytes leading to a higher 
1 glycolytic activity associated with increased fatty acid, lactate, pyruvate and ketone bodies secretion $[20,21]$. In addition, it has been proposed that glutamine participates in the crosstalk between adipocytes and cancer cells. In pancreatic cancer model, cancer cells promote the secretion of glutamine by adipocytes through the downregulation of glutaminase in adipocytes [22]. Adipose tissue lipolysis has also been observed in pancreatic cancer [15] where cancer cells promote delipidation of adipocytes and decrease the expression of genes associated with lipid metabolism [23]. Adipocyte lipolysis is also induced by leukemic cells in gonadal adipose tissue [24] and in bone marrow [25]. However, lipolysis might be different between adipocytes from bone marrow, visceral adipose tissue or subcutaneous adipose tissue. Indeed bone marrow adipocytes display a specific lipid metabolic profile compared to subcutaneous adipocytes with cholesterol biosynthesis oriented metabolism [26]. Importantly lipolysis is not induced by calorie restriction in bone marrow adipocyte due to the reduced expression of the monoacylglycerol lipase responsible of the last step of lipolysis; the hydrolysis of monoglycerides to free fatty acids and glycerol [26]. In addition with lipolysis and secretion of pro-inflammatory adipokines, cancer-associated adipocytes display fibroblast-like phenotype with the reorganisation of actin and vinculin cytoskeleton and the secretion of fibronectin and collagen 1 [27].

Among the mechanisms involved in the induction of the activated phenotype of adipocytes by cancer cells, extracellular vesicles and miRNA have been recently described to promote adipocyte lipolysis and inflammation. In lung cancer, extracellular vesicles transfer IL-6 to induce adipocyte lipolysis through STAT3 pathway [16]. In hepatocarcinoma exosomes released by cancer cells activate NFKB signalling and induce an inflammatory phenotype in adipocytes with the secretion of IL-6, IL-8 and macrophage chemoattractant protein (MCP-1) [17]. In breast cancer, the secretion of miRNA-144 and miRNA-126 by breast cancer cells is involved in adipocyte browning [20]. These miRNA are associated with the peroxisome proliferator-activated receptors PPAR $\gamma$, IRS-1 and GLUT-4 downregulation and autophagy marker and HiF-1 $\alpha$ upregulation in cancer-associated adipocytes [20]. In another model PPAR $\gamma$ is also downregulated by miR-155 secreted by breast cancer cells and could participate to metabolic remodelling in adipocytes [21].

Several other signalling pathways induced by cancer cells have been demonstrated in bone marrow adipocytes but little is known about their involvement in white adipose tissue. Leukemic cells influence bone marrow adipocytes by inducing reactive oxygen species (ROS) and oxidative stress [18] and by inducing lipolysis and a decrease in lipid metabolism gene 
expression through the secretion of Growth Differentiation Factor 15 (GDF15) [28]. Bones are the major site for prostate cancer metastasis. It has been demonstrated that prostate cancer cells activate bone marrow adipocytes through IL1- $\beta$ signalling. Besides its role in lipolysis, IL1- $\beta$ secreted by prostate cancer cells promotes a proinflammatory phenotype in adipocytes via upregulation of MCP-1 and cyclooxygenase-2 (COX-2) which is involved in the synthesis of the bioactive lipid, prostaglandin E2 (PGE2) from arachidonic acid [29].

Altogether, these studies highlighted to profound remodelling of adipocytes by cancer cells leading to the secretion of fatty acids, metabolic fuels and adipokines.

2) Regulation of tumour microenvironment by adipocytes

The modification of adipocyte phenotype by cancer cells induces a strong effect in tumour cells including macrophages, natural killer cells and endothelial cells (Fig1).

One important effect of adipocyte on tumour microenvironment is the activation of macrophages. In hepatocarcinoma it has been demonstrated that inflammatory adipocytes induced by cancer cells promote macrophage migration and their recruitment in tumours [17]. In breast cancer, adipocyte proximity also promotes macrophage migration by increasing the secretion of MCP-1 by cancer cells [30]. In addition, leptin secreted by adipocytes controls the secretion of pro-inflammatory cytokines and chemokines in macrophages and promotes macrophages differentiation [30]. Interestingly more crown-like structures, macrophages surrounding dying adipocytes, are observed in mammary adipose tissue from obese tumourbearing mice even far from the tumour compared to lean tumour-bearing mice $[30,31]$.

Beside the promotion of macrophages inflammatory phenotype and tumour promotion, adipocyte - tumour crosstalk regulates anti-tumour immune response by natural killer (NK) cells. Adipocytes decrease the natural killer cell toxicity against castration-resistant prostate cancer cells [32]. PD-L1/PD-1 and NKG2D ligand/NKG2D pathways mediate NK cell interaction with cancer cells. Secretion of leptin and IL-6 by adipocytes activates the Janus kinase (JAK)-signal transducer and activator of transcription 3 (STAT3) pathway in prostate cancer cells leading to upregulation of PD-L1 and downregulation of NKG2D ligands in prostate cancer cells. This regulation of cancer cell recognition by NK cells decreases NK cytotoxicity and promotes immune escape in castration resistant prostate cancer [32]. Also adipocytes inhibit trastuzumab-mediated antibody dependent cellular cytotoxicity by natural 
killer cells [33]. In this model NK cell cytotoxicity is not affected by adipocyte secreted factor

2 but adipocytes reduce sensitivity of tumour cells to antibody-dependent cellular cytotoxicity

3 through upregulation of survival pathways [33].

Although the mechanism is controversial, cancer-associated adipocytes promote tumour growth through modulation of endothelial cells and tumour vascularization. It has been demonstrated in hepatocarcinoma that cancer-associated adipocytes enhance endothelial cell tube formation and vascularisation in tumours [17]. Interestingly it has been demonstrated in obese mice that the activation of macrophages by adipocytes through MCP-1 IL1- $\beta$ and CXCL12 promotes vascularization and angiogenesis [31]. However in breast cancer model, high secretion of IL-6 and FGF-2 in obese condition is associated with reduced vascularization and hypoxia leading to resistance to anti-VEGF therapy [34]. In addition, resistance to anti-angiogenic therapy is mediated by adipose tissue lipolysis and lipid metabolic reprogramming in cancer cells (FFA uptake and FAO) [35]. Therefore it has been proposed to target both angiogenesis and FAO which have shown promising tumour growth reduction [35].

Because of its wide range of effect, adipose tissue highly influence tumour microenvironment by promoting macrophage infiltration, tumour inflammation and regulating immune cell cytotoxicity and angiogenesis. More studies are needed to better characterize the role of cancerassociated adipocytes on tumour cells. Nevertheless, combination therapy acting on both adipose tissue and tumour microenvironment could be promising strategies to reduce the impact of cancer-associated adipocytes and limit treatment resistance.

3) Regulation of cancer cells by adipocytes

Besides its effect on tumour microenvironment, cancer-associated adipocytes influence cancer cells per se leading to tumour growth, metastasis and treatment resistance. These effects are mediated by the wide range of adipokines, glutamine, ketone bodies, extracellular vesicles and fatty acids secreted by cancer-associated adipocytes (Table $\mathbf{1}$ and Fig1).

a) adipokines

Several hormones, cytokines or growth factors secreted by adipocytes have been associated with cancer cell properties and tumour progression.

i) Leptin 
1 Leptin, one major adipokine secreted by adipocytes, stimulates the proliferation and the migration of cancer cells [36, 37]. Mechanistically leptin through its fixation to its receptor ObR in cancer cells activates pro-survival pathways like JAK/STAT3, Akt and c-Jun N-terminal kinase (JNK) [37, 38]. The activation of these signalling pathways induces the transcription of genes involved in cellular proliferation and invasiveness like the telomerase reverse transcriptase, IL-6, transforming growth factor $\beta$ (TGF $\beta$ ), matrix metalloproteinases (MMP) MMP9 and MMP13 [39]. Interestingly the expression of leptin receptor is increased in tumours compared to normal tissues [39]. Leptin is also secreted by adipose stem cells and promotes cancer cell proliferation, migration, invasion and metastasis [40]. Moreover these effects are more pronounced with adipose stem cells from obese patients [40]. As a consequence mice lacking the leptin receptor display a reduced tumorigenicity, tumour growth and metastasis appearance through a reduction of the ERK1/2 and JAK/STAT3 signalling [41]. Interestingly leptin signalling is also associated with metabolic remodelling in cancer cells. Mammary cancer cells lacking the leptin receptor show a decrease in glycolysis and an increase in mitochondrial oxidation [41].

Besides its important role on cancer growth and metastasis, the activation of leptin pathway in cancer cells is also associated with resistance to therapy. In melanoma cells, the proximity of adipocytes induces the activation of Akt and MEK/ERK pathways by leptin and leptin receptor ObR. Consequently, the activation of these signalling pathways reduces apoptosis induced by chemotherapeutic drugs, including the alkylating agent cisplatin, the anti-microtubule agent docetaxel, and the histone deacetylase inhibitor SAHA [42]. It has also been demonstrated that mature adipocytes in bone marrow protect myeloma cells against chemotherapy through autophagy activation. The secretion of leptin and adipsin by bone marrow adipocytes increases the expression of autophagic proteins and reduces apoptosis induced by melphalan (alkylating agent), bortezomib (proteasome inhibitor), dexamethasone (corticosteroid) or doxorubicin (topoisomerase inhibitor) in myeloma cells [43].

ii) Adiponectin

In addition to leptin, nutrient and energy homeostasis are regulated by another important adipokine, the adiponectin. It has been demonstrated in hepatocarcinoma that adiponectin antagonizes the effects of leptin in the activation of STAT3 and Akt and consequently in the stimulation of proliferation, migration, invasion and tumour growth [38]. The balance between leptin and adiponectin seems to be an important factor for the proliferation of cancer cells [44]. 
1 This could be an important parameter for the effect of obesity in cancer promotion since the level of leptin is often found increased and adiponectin decreased in obese patients.

The reduction in adiponectin levels in colorectal cancer patients compared to healthy control was associated with an increase in colon tumour development [45, 46]. Adiponectin downregulation was linked with an increase in cytokine secretion, STAT3 activation and a decrease in AMP-activated protein kinase (AMPK) activation [46]. Reciprocally, adiponectin supplementation mediates apoptosis of colon cancer cells through the activation of caspase-3 via increased activation of JNK and AMPK [47]. However, the role of adiponectin in cancer seems to be more complex. Some studies suggested on the opposite that a high level of adiponectin is associated with increased risk of breast cancer development [48]. The discrepancy in the effects of adiponectin in cancer might be due to the presence of two adiponectin forms. Adiponectin exists in the full-length form and in the truncated form named globular adiponectin, which contains the carboxy-terminal globular domain. Unlike the fulllength form, globular adiponectin promotes breast cancer cell invasive morphology, migration and invasion. Although the mechanisms are not completely described, autophagy induction participates in the promotion of cancer cell invasiveness by globular adiponectin [49].

Altogether, these studies demonstrated the complex roles of leptin and adiponectin in cancer progression. Because of the opposite effects of lectin and adiponectin on obesity and on cancer cells, studies investigating both adipokines will be more informative than separate studies. These studies are needed to better clarify the influence of these important adipokines and to develop the targeting of these signalling pathways to reduce cancer growth.

iii) IL-6

Among adipokines, the pro-inflammatory cytokine IL-6 has been widely linked with cancer progression. IL-6 secretion by adipocytes has been associated with increased breast cancer cell aggressiveness $[12,50]$. Adipocyte proximity leads to more aggressive morphology in breast cancer cells associated with epithelial to mesenchymal transition (EMT), a high invasiveness in vitro and metastasis in vivo (Dirat et al., 2011). IL-6 secreted by adipocytes is involved in these pro-invasive effects (Dirat et al., 2011). In another study IL-6 and MCP-1 secreted by adipocytes promote breast cancer cell migration in vitro, however adipocytes lead to an increase in epithelial marker E-Cadherin (Fujisaki et al., 2015). Interestingly in these studies breast cancer cell invasiveness is promoted by cancer-associated adipocytes compared to normal breast adipocytes isolated from patients $[12,50]$. 
1 The effects of IL-6 in cancer cells are mainly mediated by STAT3 activation [51, 52]. In breast cancer cells the activation of STAT3 and Akt signalling by leptin and IL-6 increases the expression of the Procollagen-Lysine,2-Oxoglutarate 5-Dioxygenase 2 (PLOD2) (He et al., 2018). This protein, involved in collagen deposition, is important for matrix remodelling in extracellular tumour environment. Therefore the expression of PLOD2 induced by adipocytes promotes cancer cell migration, invasiveness and EMT (He et al., 2018). Interestingly PLOD2 downregulation decreases tumour growth and metastasis in mice and high PLOD2 expression is associated with poor prognosis in breast cancer patients (He et al., 2018). In ovarian cancer, the activation of STAT3 by adipocyte-derived IL-6 is associated with chemoresistance. It has been demonstrated that adipocytes promote the expression of the pro-survival member of the BCL-2 family, BclXl and induce resistance to carboplatin [51]. In addition, IL-6 secreted by adipocytes is associated with resistance to radiotherapy in breast cancer cells. Adipocytes increases the activation of the DNA-damage response protein Chk1 after irradiation through IL-6 and STAT3 activation [53].

iv) Other adipokines

Several other adipokines have been associated recently with cancer progression mainly in breast cancer such as resistin, adipsin, Lipocalin-2 or insulin-like growth factor binding protein-2 (IGFBP-2). In breast cancer cells, resistin activates the TLR4/NF- $\kappa$ B/STAT3 pathway to stimulate EMT and stemness. Consequently resistin increases migration, invasion, anoikis resistance and tumour growth [54]. Importantly high level of resistin is found in breast cancer patients and correlates with cancer progression and poor prognosis [54]. Adipsin (complement factor $\mathrm{D}$ ) is a complement factor that cleaves complement factor $\mathrm{B}$ into $\mathrm{Ba}$ and $\mathrm{Bb}$ leading to the cleavage of $\mathrm{C} 3$ into $\mathrm{C} 3 \mathrm{a}$ and $\mathrm{C} 3 \mathrm{~b}$ to activate the alternative complement pathway. It has been demonstrated that Adipsin/C3a pathway activates the $\mathrm{C} 3$ a receptor in breast cancer cells, which increases cell proliferation and sphere forming efficiency. In mice experiments, adipsin is involved in tumour growth promotion by adipocytes [55]. Lipocalin-2, which secretion by adipocytes is increased in obesity, has been shown to promote breast cancer cell proliferation and migration. Although the mechanism is not clearly understood, the effects of Lipocalin-2 seem to be linked with the expression of 3-hydroxybutyrate dehydrogenase 2, an enzyme involved in iron metabolism [56]. Among the adipokines involved in cancer progression, IGFBP-2 secreted by adipocytes in proximity with breast cancer cells stimulates breast cancer cell invasiveness. IGFB-2 is associated with increased expression of MMP2 by breast cancer cells [57]. Matrix proteases are also increased by adipocytes conditioned medium in several 
cancer models such as MMP9 and MMP2 in melanoma and colon cancer cells [58] and cellsurface urokinase-type plasminogen activator in breast cancer cells [6] to promote cancer cell migration and invasiveness. It has been demonstrated in an interesting model of obesity independent of high-fat diet or leptin deficiency that the secretion of osteopontin is associated with prostate cancer cell invasiveness [59]. In this model p62 (an autophagic cargo) deficiency in adipose tissue increases adiposity and metabolic remodelling of adipose tissue. The migration and invasion of prostate cancer cells were enhanced in presence of p62 deficient adipocyte conditioned medium. The effect of osteopontin secreted by adipocytes was mediated by an increase in the carnitine palmitoyltransferase I (CPT1) expression and fatty acid oxidation (FAO) [59].

Like leptin and IL-6, besides these important roles on cancer progression and metastasis, the other adipokines have been linked with resistance to chemotherapy. It has been demonstrated that adipocytes promote resistance to trastuzumab in HER2- positive breast cancer cells through the secretion of GDF15, which activates the Akt survival pathway. In the same model Leptin promotes resistance to lapatinib but not to trastuzumab [60]. Adipose tissue and obesity are also associated with the relapse of acute lymphoblastic leukaemia. In murine models, leukaemia cells migrate through adipose tissue. The authors demonstrate in vitro that Stromal derived factor-1 secreted by adipocytes promotes the migration of leukaemia cells towards adipocytes. The localisation of leukaemia cells in adipose tissue protects them from the chemotherapeutic drugs daunorubicin and vincristine [61].

Altogether these studies demonstrated that through the secretion of a wide range of adipokines, adipocytes play a major role in cancer growth, metastasis and treatment resistance.

b) Glutamine and ketone bodies

Although the mechanism is not entirely described, it has been demonstrated that cancerassociated adipocytes secrete glutamine, which is taken up by prostate cancer cells. Glutamine secreted by adipocytes increases the proliferation of pancreatic cancer cells likely through its metabolic function [22]. This secretion of glutamine by adipocytes can be important for leukaemia which are highly dependent on glutamine metabolism and for which L-asparaginase is used as treatment. Indeed it has been demonstrated that the expression of glutamine synthetase is increased in bone marrow adipocytes after L-asparaginase treatment and that 
adipocyte secretion of glutamine protects leukaemia cells from L-asparaginase cytotoxicity [62].

In addition to the secretion of adipokines, fatty acids or glutamine by adipocytes, the secretion of ketone bodies such as $\beta$-hydroxybutyrate could have an important role on epigenetic regulation of gene expression and cancer progression [63]. It has been demonstrated that $\beta$ hydroxybutyrate secreted by breast adipocytes, promotes breast cancer cell proliferation and tumour growth in cells expressing its transporter MCT2. $\beta$-hydroxybutyrate through HDAC inhibition induces the expression of tumour promoting genes such as IL-1 $\beta$ and Lipocalin- 2 in cancer cells. MCT2, IL-1 $\beta$ and Lipocalin-2 high expression was associated with poor prognosis in breast cancer patients [63].

\section{(1)}

c) Extracellular vesicles

Recently the demonstration of the secretion of extracellular vesicles by adipocytes has provided new evidence for the understanding of the interactions between adipocytes and tumours. Extracellular vesicles carries proteins, RNAs or lipids and are important mechanism for cellular communications.

In melanoma it has been demonstrated that extracellular vesicles carry proteins involved in fatty acid and glucose oxidation along with metabolic substrates inducing metabolic reprogramming in cancer cells $[64,65]$. These extracellular vesicles are involved in the promotion of cancer cell migration and invasion by adipocytes $[64,65]$. Furthermore adipocytes grown in high-fat diet have a higher secretion of extracellular vesicles which induce a more pronounced effect on fatty acid oxidation in cancer cells due to enhanced lipid transfer but not through protein transfer $[64,65]$.

It has been demonstrated that extracellular vesicles secreted by adipocytes can also carry proteases. In a lung cancer model, adipocyte exosomes are used to transfer MMP3 in cancer cells. MMP3 activates MMP9 and promotes cellular invasiveness and metastasis in vivo. In lung tumour patients the protein level of MMP3 was increased in obese patients compared with non-obese patients, suggesting that obesity can amplify this mechanism of MMP3 secretion through exosomes to promote metastatic dissemination [66].

Extracellular vesicles are important carriers of non-coding RNA. Adipocyte exosomes contains miR-23a and miR-23b, which are transferred in hepatocellular carcinoma cells. The von Hippel- 
Lindau (VHL) protein is a direct target of these miRNA. Consequently, miR23a/b increases hypoxia inducible transcription factor (HIF-1) signalling in cancer cells leading to an increase in cell proliferation, migration, resistance to 5 -FluoroUracile and tumour growth. miR23a/b was found enriched in exosomes from high body fat hepatocellular carcinoma patients. Moreover VHL low expression and HIF-1 $\alpha$ high levels was associated with poor patient prognosis [67]. In another study, the transfer of miR-21 form adipocyte exosomes to ovarian cancer cells promotes paclitaxel resistance through targeting the Apoptotic protease activating factor 1 [68].

\section{d) Fatty acids}

It is now well described that fatty acids released by adipocytes in proximity with tumours are up taken by cells form breast cancer [69], ovarian cancer [13], prostate cancer [70], melanoma [71], colon cancer [72], pancreatic cancer [15] and leukaemia cells [24]. Fourier transform infrared (FTIR) microspectroscopy has allowed to evidence the lipid translocation from adipocytes to prostate cancer cells [73]. In addition in vitro co-culture pulse chase assays has shown a direct transfer of fatty acids from adipocytes to melanoma cells [74]. To avoid lipotoxicity excess free fatty acids are often stored esterified in lipid droplets (LD) which are intracellular organelles formed of a phospholipid monolayer surrounding neutral lipids (triacylglycerol and sterol esters). LD accumulation have been observed in several tumours and is associated with aggressiveness and poor prognosis [75]. This accumulation of LD depends also on tumour microenvironment factors like hypoxia, which is associated with LD accumulation through upregulation of fatty acid binding proteins FABP7 and FABP3. LD are essentials for ROS removal, NADPH production and survival in condition of reoxygenation [76]. Free fatty acids up taken from the tumour environment or released from lipid droplets exert major roles for membrane structures, metabolism as substrates for fatty acid oxidation (FAO) and signalling through transcription factor or oxidative stress.

i) Metabolic roles

Fatty acids are substrates for FAO to fuel the citric acid cycle and the mitochondrial electron transport chain. Interestingly the rate-limiting enzyme of FAO CPTI, involved in the delivery of fatty acids to mitochondria, are upregulated in cancers [77]. Furthermore in non-glycolytic tumours, as prostate adenocarcinoma, fatty acid uptake could be the major energetic source [69, $78] 1$. 
1 The interaction between adipocytes and cancer cells through fatty acid transfer is well described in breast and ovarian cancers. In breast cancer cells, it has been demonstrated that co-culture with adipocytes increases lipid droplet number. Interestingly fatty acids stored in lipid droplets in cancer cells are released over time through the action of the adipose triglyceride lipase (ATGL) or through lysosomal-dependent pathway; the lipophagy [64]. These fatty acids induce profound changes in breast cancer cell metabolism with an increase in FAO, and in glucose and glutamine oxidation $[69,79,80]$. Unexpectedly this increase in mitochondrial oxidation is uncoupled to ATP production which comes mainly from glycolysis [69]. This uncoupled mitochondrial oxidation leads to a decrease in ATP content and consequently AMPK activation and ACC phosphorylation redirects lipids towards FAO instead of fatty acid synthesis leading to a metabolic remodelling oriented towards fatty acid oxidation [69].

The metabolic effect of adipocyte proximity is also observed in colon and ovarian cancers and leukaemia. Adipocytes induce an accumulation of lipid droplets and metabolic remodelling with an increase in oxygen consumption from FAO and a decrease in oxygen consumption from glucose in colon cancer cells. This study provides mechanistic details linking AMPK activation with autophagy and survival under nutrient deprivation [72]. Fatty acids are also transferred from adipocytes into ovarian cancer cells and used for FAO inducing AMPK activation [13]. In this model ACC is inhibited by AMPK activation but also by the activation of the saltinducible kinase SIK2 to promote fatty acid oxidation [81]. Indeed this study demonstrates that fatty acids transferred from adipocytes increase the intracellular calcium concentration in ovarian cancer cells through the activation of G-protein coupled fatty acid receptor and subsequent phospholipase $\mathrm{C}$ activation. SIK2 is activated by the rise in intracellular calcium leading to ACC phosphorylation and the activation of the PI3K/Akt pro-survival pathway [81]. In leukaemia cells, adipocytes promote also metabolic changes with enhanced FAO and glucose metabolism but again uncoupled to ATP production and associated with AMPK activation and autophagy markers. The authors proposed that fatty acids might activate PPAR $\gamma$ transcription factor to induce the expression of fatty acid transporters FABP4 and CD36 and anti-apoptotic proteins [82]. Altogether, these studies shown that AMPK activation and mitochondrial uncoupling seems to be key mechanisms in cancer metabolic reprogramming induced by adipocytes. This suggests important roles of mitochondrial metabolites, apart from energy production through ATP, for cancer cell metabolism and might be favourable to resistance to cell death and survival as demonstrated in leukaemia [83]. 
Interestingly, the expression of the actors of these fatty acid induced pathways is upregulated

2 in cancer cells. ATGL is overexpressed in breast tumours compared to normal tissues and 列 correlates with aggressiveness [69]. Moreover ATGL expression is increased in breast tumours in contact with the adipose tissue [69]. SIK2 is overexpressed in ovarian cancer cells metastasised in adipose tissue compared to cells from the primary tumour [81]. Lastly the expression of CPT1 is increased by high fatty acid condition [79]. In human cancer patients CPT1 gene alteration is associated with poor prognosis in ER positive breast cancer patients [79].

The metabolic role of fatty acids transferred from adipocytes in cancer cells is associated with cancer survival and metastases. Fatty acids derived from adipocytes induce morphology changes in cancer cells associated with EMT [15, 69, 72] and relocalization of lipid droplets and mitochondria in cellular protrusions [64]. This phenotype promotes cancer cell migration $[15,64,72,80]$, invasiveness and metastasis $[69,81]$. However in a breast cancer model fatty acids promote cancer cell proliferation but the increase in migration depends on adipokines [79]. In colon cancer cells the stimulation of autophagy by adipocyte proximity promotes survival in nutrient-deprivation condition through the metabolic use of fatty acids [72].

ii) Oxidative stress and survival

Besides their metabolic roles, fatty acids are well known signalling molecules through freefatty acid sensing G-protein coupled receptors (FFA1-4) and intracellular transcription factors of the PPAR family.

Therefore, fatty acids are involved in cell death protection and particularly in cancer treatment resistance. In several cancer types, adipocytes provide protection against cancer treatment by providing metabolic fuels [24] and preventing apoptosis [15, 84]. Fatty acids, through the functioning of electron transport chain in mitochondria and through modulation of NADPH oxidase have been associated with either the promotion or the reduction of oxidative stress and ROS [85]. In leukaemia cells adipocytes promote survival by reducing oxidative stress induced by daunorubicin and by radiation [18]. In this model, leukaemia cells promote a Nrf2-mediated oxidative stress in adipocytes with an increase in glutathione synthesis which is partially involved in adipocyte protection of leukaemia [18]. Secreted factor induced by oxidative stress in adipocytes are involved in the reduction of oxidative stress induced by daunorubicin and by radiation in leukaemia cells [18]. In gastric cancer cells, adipocyte proximity decreases 
oxidative stress induced by cell detachment through increase in NAPDH production and glutathione leading to anoikis resistance and metastasis in mice [86].

However fatty acids and FAO are also associated with enhanced oxidative stress and ROS production. Indeed adipocyte proximity induces fatty acid metabolic remodelling and increases ROS and lipid peroxidation in ovarian cancer cells. Although the mechanism was not described, the FAO and ROS production induced by adipocytes are associated with proliferation and resistance to carboplatin [87]. In prostate cancer cells intracellular ROS are also increased by adipocyte proximity and lipid transfer [70]. In this model ROS are produced by NOX5 which expression increases in presence of adipocytes and in human tumours close to adipose tissue. ROS production is associated with HIF-1 signalling, MMP14 expression and cancer cell invasiveness [70]. This lipid/ROS/HIF signalling pathway is potentiated by obese adipocytes [70]. In another model of prostate cancer it has been found that bone marrow adipocyte promotes the expression of glycolytic genes and glycolytic metabolism through the stabilisation of HIF-1 $\alpha$ [14]. HIF-1 $\alpha$ target genes are increased in prostate cancers in contact with bone adipocytes compared to subcutaneous tumours and also with high fat diet [14]. The same team demonstrated that ROS produced by adipocyte proximity are associated with overexpression of the oxidative stress enzyme Heme oxigenase 1 and ER-stress protein BIP in prostate cancer cells. These oxidative and ER-stress pathways promote cancer cell invasion and survival in bone [88].

\section{4) Targeting fatty acid transporters}

Since fatty acids play a major role on cancer progression, reducing fatty acid transport from adipocytes to cancer cells might be an attractive target for cancer therapy

For a long time it has been through that, fatty acids diffuse freely through the plasma membranes and integrate to the phospholipid bilayer. However it is now clear that several membrane transporters are involved in lipid uptake such as CD36, Fatty Acid Binding Proteins (FABPs) and Fatty Acid transport proteins (FATs) which have all been found upregulated in cancer [89]. Furthermore, hypoxia, a common marker of tumour microenvironment has been linked with fatty acid transporter expression. Indeed the expression of several FA transporters is increased in hypoxia through HIF-1 $\alpha$ signalling like FABP7, FABP3 [76] and FABP4 [90]. 
1 Obviously fatty acid transporters have been involved in the interactions between adipocytes and cancer cells and represent interesting targets to reduce cancer promotion by adipose tissue. CD36 is one of the most characterized transporter in cancer cells. Interestingly CD36 is highly expressed in metastasis compared to primary tumour and its expression in metastasis-initiating cells is associated with metastasis dissemination and poor prognosis [91, 92]. It has been demonstrated that CD36 expression is induced in ovarian and breast cancer cells by adipocyte proximity $[91,93]$. Lipid transport through CD36 is involved in the regulation of cancer cell metabolism and in the stimulation of cancer progression and metastasis [91, 93]. Interestingly the inhibition of CD36 expression or activity using blocking antibody or Sulfo-N-succinimidyl oleate reduces adipocyte-induced fatty acid uptake and subsequent migration, invasion, tumour growth and metastasis $[91,93]$.

The expression of FABP4 is also increased by adipocyte proximity in ovarian cancer $[13,87$, 90]. Furthermore FABP4 expression is also upregulated in adipocytes by leukaemia cells [25]. Fatty acid transport through FABP4 participates in tumour growth, metastasis and resistance to carboplatin in ovarian cancer [13, 87] and survival in leukaemia [25]. Downregulation of FABP4 expression reduces leukemic cell viability and metastasis in ovarian cancer model [13, 87]. A small molecule has been developed to inhibit FABP4, BMS309403 and shows promising reduction in tumour growth in breast cancer and metastasis in ovarian cancer models [87, 94]. Unexpectedly FABP4 has also been linked with DNA methylation in acute myeloid leukaemia [95]. FABP4 activates NFKb/IL-6/STAT3 pathway leading to an increase in the expression of DNA methyltransferase 1. FABP4 induces tumour suppressor genes silencing by hypermethylation and leads to aggressive leukaemia [95]. High expression of FAPB4 in acute myeloid leukaemia patients is associated with poor patient survival [95]. Interestingly high circulating FABP4 was found in obese breast cancer patients and promotes cancer stremness and aggressiveness [94]. FABP5 is also overexpressed by breast cancer cells in contact with adipocytes [78]. FABP5 is involved in fatty acid trafficking after ATGL-dependant lipolysis leading to increased migration and invasiveness by cancer cells [78]. High FABP5 expression in human breast cancer patients correlates with high grade and ER negative and triple negative tumours [78].

Lastly the fatty acid transport protein 1 (FATP1) has been involved in fatty acid transfer from adipocytes to melanoma cells [74]. In melanoma patients FATP1 expression is higher in metastasis close to subcutaneous adipose tissue compared to primary tumour. FATP1 inhibition by the small-molecule inhibitor Lipofermata decreases cancer cell growth and invasion [74]. In 
clear renal cell carcinoma high FATP4 expression is found in cancer compared with normal tissue and is associated with poor prognosis [96].

Altogether these studies provide the proof of concept that fatty acid transport protein might be promising molecular targets to disrupt the interaction of tumours with the surrounding adipose tissue. This could be of major interest in the context of obesity. These proteins represent interesting avenues for diagnosis and also as therapeutic targets to reduce tumour growth and metastasis.

\section{5) Modification of adipose tissue composition}

The interaction between adipocytes and cancer cells involves mainly adipokines and fatty acids. Most of the studies have focused on fatty acid quantity, however the composition of adipose tissue and tumours in fatty acid length and unsaturation could have important role. Indeed the structural and signalling roles of fatty acids highly depend on the different lengths and degrees of unsaturation of fatty acids which are associated with oxidative stress, membrane fluidity and specific membrane domains as the lipid rafts [97]. The role of saturated and unsaturated fatty acids in cancer is still controversial. On one hand some studies show that a high level of saturated fatty acids in tumours are associated with aggressive breast cancers [98]. On the other hand other studies have shown that mono and polyunsaturated fatty acids are associated with cancer aggressiveness since higher polyunsaturated fatty acids level was associated with epithelial to mesenchymal transition in breast cancer cells [99]. In addition the expression of stearoyl CoA desaturase-1, enzyme catalysing the conversion of saturated fatty acids into monounsaturated fatty acids, have been found increased in different tumour type and associated with lipid metabolism and cancer progression [100].

Adipocyte proximity induces global change in lipid composition in cancer cells [87, 101], however mechanisms involving specific lipids have been demonstrated. Among fatty acids modified in cancer cells by adipocyte proximity, palmitic acid has been found increased and associated with high proliferation in melanoma cells [71]. It has been demonstrated that palmitic acid activates Akt survival pathway leading to increased proliferation of melanoma cells [71]. In gastric cancer cells, adipocyte proximity induces an increase in oleic acid which promotes cancer cell invasiveness through AKT activation [102]. Arachidonic acid found in conditioned media from adipocytes activates Akt in ovarian cancer cells and contributes to chemoresistance by inhibiting cisplatin induced apoptosis [103]. Arachidonic acid metabolite PGE2 was also 
associated with chemoresistance in prostate cancer cells. PGE2 provided by adipocytes induces prosurvival pathway and resistance to docetaxel [29]. Lastly it has been shown that mammary adipose tissue contains lysophosphatidic acid (LPA) and lysophosphatidylcholine (LPC) for which breast cancer cells express the receptor LPAR1/3 [104]. LPA activates Akt in cancer cells leading to proliferation and protection from cell death [104].

Therefore the role of fatty acids in the interaction between adipose tissue and tumours seems complex. The study of adipose tissue composition could be more interesting than its quantity in the context of cancer progression as demonstrated by the lipidome analysis of breast and prostate adipose tissue that can be used to predict the risk of cancer progression $[105,106]$. Interestingly the lipid composition of adipose tissue correlates with past dietary intakes and therefore can be changed by dietary supplements or dietary restrictions in lipids. For breast cancer, it has shown that a low level of long-chain n-3 polyunsaturated fatty acids (PUFA, eicosapentaenoic acid, EPA and docosahexaenoic acid, DHA) in breast adipose tissue is associated with tumour multifocality [107], parameter associated with poor prognosis. In prostate cancer, the fatty acid profile is differently associated with cancer aggressiveness in Africane Caribbeans and Caucasians [106]. Among fatty acids associated with prostate cancer aggressiveness, linoleic acid and eicosapentaenoic acid exert anticancer effects by reducing cancer cell migration through regulation of calcium signalling and the EMT transcription factor Zeb1 [108].

\section{$\underline{\text { Conclusion }}$}

Altogether these studies highlight the recent demonstration of the reciprocal interaction of adipose tissue with tumours. Among factors secreted by adipocytes, a wide range of adipokines and fatty acids has been involved. All these studies have been done on in co-culture models or using conditioned media. The recent development of 3D models will brings more information about the relationship in complex tissues. These models have been developed for prostate cancer using 3D culture of prostate cancer spheroids with bone marrow-derived adipocytes [109] or with preadipocytes for breast cancer [110, 111]. First studies using 3D models have confirmed the effects of adipocytes on cancer cells. In 3D cultures adipocyte proximity induces a change in prostate cancer morphology and increases Akt signalling and proliferation [112]. In 3D model of breast tumour, leptin and leptin receptor was expressed and adipocyte proximity induces major transcriptional changes in breast cancer cells including genes involved in cell 
1 proliferation, angiogenesis and IL-6 pathway [110]. These 3D models including cells from

2 tumour microenvironment such as macrophages, endothelial cells or fibroblast will be useful to

3 better characterize the effects of adipose tissue proximity on tumours. In addition, studies 4 investigating the effects of fatty acid composition on cancer cells are needed. For example

5 Raman microspectroscopy have been used to investigate lipid droplet composition in prostate

6 cancer cells [113].

7 Although several mechanisms involving adipokines or lipids have been discovered to play a 8 major role on cancer progression some studies are still needed to understand the role of fatty 9 acid transport and composition in order to propose innovative therapies, based on nutritional 10 adjuvant interventions, or on the targeting of new signalling pathways to interfere with this 11 cellular cooperation. 
2 We thank all our colleagues from the Université de Tours-Inserm UMR1069 for all constructive 3 discussion and Ms. Catherine Le Roy for secretary and administrative assistance. The work 4 performed at the Universite de Tours-Inserm UMR1069 was supported by the Inserm, the

5 "Ligue Nationale Contre le Cancer - Inter-région Grand-Ouest", the Fondation ARC and the 6 "Cancéropole Grand-Ouest".

7 Finally, we wish to apologize to all researchers whose relevant works, owing to the limited length of this article format, could not be cited in this review.

9

$\underline{\text { Figure legend }}$

Fig1: Molecular interplay between adipocytes, cancer and non-cancer cells in tumours. Cancer cells induce an activated phenotype in adipocytes characterized by delipidation and increase in the secretion of pro-inflammatory adipokines (blue $\downarrow$ and $\uparrow$ ). These cancer-associated adipocytes promote tumour growth, metastasis and treatment resistance through the secretion of a wide range of adipokines and metabolites including fatty acids. The orange arrows indicate the adipocytes secretions and the black arrows the main mechanisms demonstrated in cancer cells. In addition, cancer-associated adipocytes also act on tumour macrophages, natural-filler cells and endothelial cells (indicated in green). LD: lipid droplet, FA: fatty acid, EV: extracellular vesicles, TF: transcription factor, ROS: reactive oxygen species, TG: triglyceride, PL: phospholipid. 


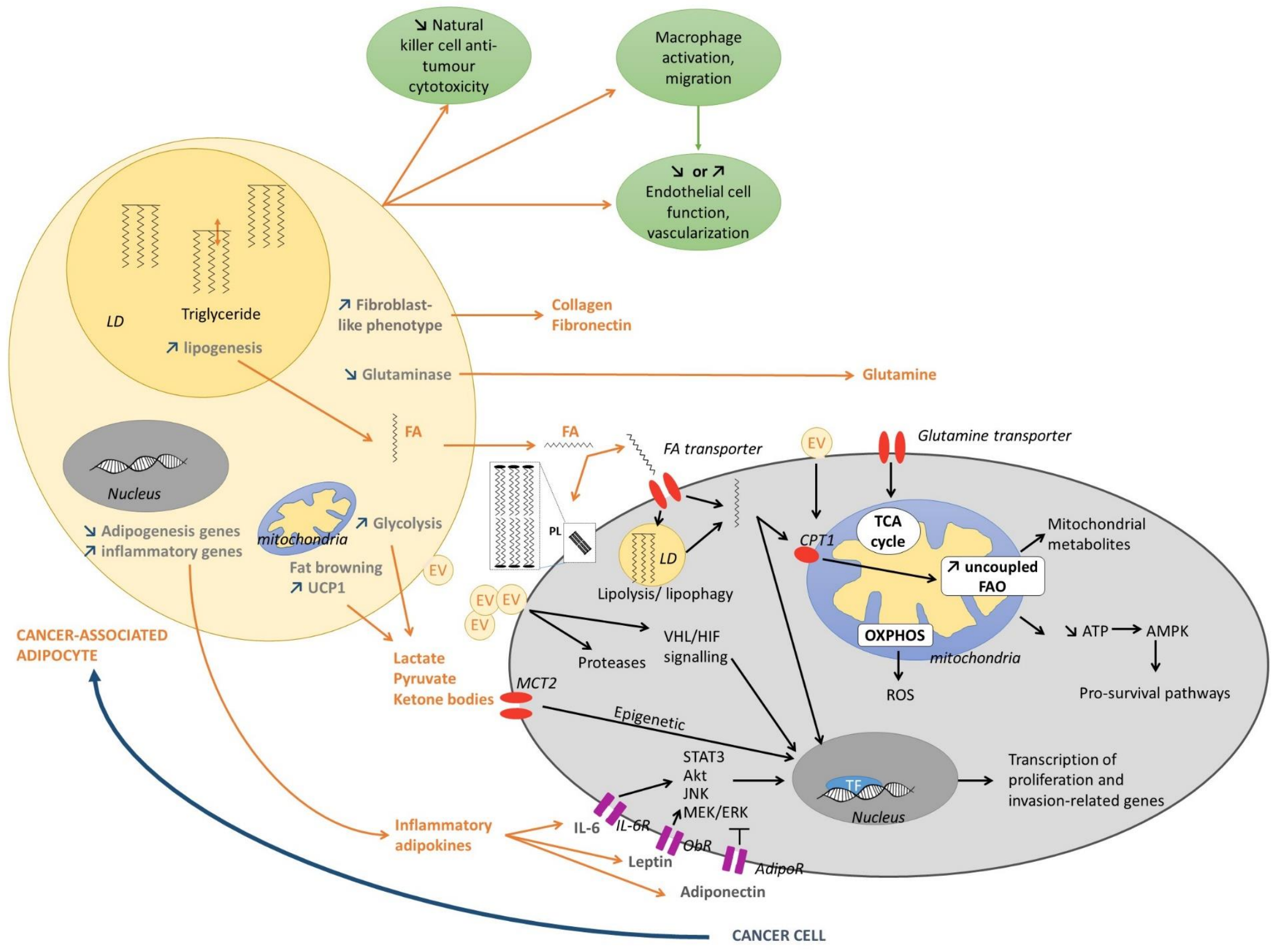




\begin{tabular}{|c|c|c|c|c|}
\hline Tissue & Secretion involved & Molecular mechanism & Effect on tumour & $\begin{array}{l}\text { Referen } \\
\text { ce }\end{array}$ \\
\hline \multirow{19}{*}{ Breast } & FA & FA uptake & proliferation, migration, invasion & [93] \\
\hline & FA & metabolic remodelling, EMT & invasion, metastasis & [69] \\
\hline & FA (LPA) & pAkt & proliferation, survival & [104] \\
\hline & FA and other & metabolic remodelling & proliferation (FA), migration (other) & [79] \\
\hline & $\begin{array}{l}\text { IL6, MMP9, } \\
\text { MMP11, PAI }\end{array}$ & partial EMT & invasion, metastasis & {$[12]$} \\
\hline & Resistin & TLR4/NF-кB/STAT3 pathway, EMT & migration, invasion, anoikis resistance, tumour growth & [54] \\
\hline & Adipsin & $\mathrm{C} 3 \mathrm{a} / \mathrm{C} 3 \mathrm{aR}$ & proliferation, sphere forming ability, tumour growth & [55] \\
\hline & IL-6 & DNA damage response & radioresistance & [53] \\
\hline & IL-6 MCP-1 & EMT & migration & [50] \\
\hline & IL6, Leptin & JAK/STAT3 Akt PLOD2 & migration, invasion, EMT, tumour growth and metastasis & [52] \\
\hline & Leptin & macrophages migration & tumour growth & [30] \\
\hline & Leptin & & resistance to lapatinib & [60] \\
\hline & IGFBP2 & MMP2, Ecadherin & migration, invasion & [57] \\
\hline & Lipocalin 2 & & proliferation, migration & [56] \\
\hline & gadiponectin & autophagy & invasion & [49] \\
\hline & GDF15 & Akt & resistance to trastuzumab & [60] \\
\hline & $\beta$-hydroxybutyrate & epigenetic & tumour growth & [63] \\
\hline & $\mathrm{uPa}$ & pAkt & migration & [6] \\
\hline & $?$ & metabolic remodelling, & proliferation, migration & [80] \\
\hline \multirow{8}{*}{ Leukemia } & FA & metabolism & survival, tumour growth & [25] \\
\hline & FA & metabolism & survival, chemoresistance & [24] \\
\hline & FA, Adiponectin & AMPK, metabolism & survival & [82] \\
\hline & Leptin & ? & proliferation, migration & [36] \\
\hline & SDF1 & $?$ & migration, chemoresistance & [61] \\
\hline & soluble factors & ROS & chemoresistance & [18] \\
\hline & $?$ & $?$ & chemoresistance & [84] \\
\hline & $?$ & $?$ & chemoresistance & [114] \\
\hline \multirow{6}{*}{ Ovarian } & FA & metabolism & migration, invasion, metastasis & [13] \\
\hline & FA & Ca dependant activation of SIK2, metabolism & metastasis & [81] \\
\hline & $\begin{array}{c}\text { FA (arachidonic } \\
\text { acid) }\end{array}$ & Akt, cisplatin-induced apoptosis & chemoresistance & [103] \\
\hline & FA & FABP4 expression, metabolism, ROS & metastasis, chemoresistance & [87] \\
\hline & FA & CD36, metabolism & invasion, migration, adhesion, clonogenicity, metastasis & [91] \\
\hline & IL6 & STAT3 & chemoresistance & [51] \\
\hline
\end{tabular}




\begin{tabular}{|c|c|c|c|c|}
\hline & Exosome & miR-21 & chemoresistance & [68] \\
\hline \multirow{7}{*}{ Prostate } & FA (palmitic acid) & ROS, metabolism & invasion & {$[70]$} \\
\hline & FA (PGE2) & HIF & chemoresistance & {$[14,29]$} \\
\hline & osteopontin & metabolism & proliferation, migration, invasion & [59] \\
\hline & Leptin and IL6 & JAK/STAT & immune escape & [32] \\
\hline & Leptin & JNK & proliferation of androgen independent cells & [37] \\
\hline & $?$ & metabolism, HIF & migration & {$[14]$} \\
\hline & ? & ER stress, ROS & survival, invasion, tumour growth & [88] \\
\hline \multirow{6}{*}{ Melanoma } & FA (palmitic acid) & Akt, metabolism & proliferation, tumour growth & [71] \\
\hline & FA & metabolism, FATP expression & proliferation, invasion, metastasis, tumour growth & [74] \\
\hline & Leptin & Akt, mTor, ERK/MEK & chemoresistance & [42] \\
\hline & exosome & metabolism & migration, invasion, metastasis & [65] \\
\hline & $\begin{array}{l}\text { extracellular } \\
\text { vesicles }\end{array}$ & metabolism & migration & {$[64]$} \\
\hline & $?$ & Akt, mTor & proliferation, migration, invasion & [58] \\
\hline \multirow{6}{*}{$\begin{array}{c}\text { Hepatocarcino } \\
\text { ma }\end{array}$} & Adiponectin & AMPK, C-Jun & apoptosis & [47] \\
\hline & $\begin{array}{c}\text { Adiponectin } \\
\text { deficiency }\end{array}$ & inflammation & tumour growth & [46] \\
\hline & Adiponectin, Leptin & $\begin{array}{l}\text { Adiponectin antagonizes leptin activation } \\
\text { STAT3, Akt }\end{array}$ & proliferation, migration, invasion, tumour growth & {$[38]$} \\
\hline & Leptin & STAT3, hTERT & $\begin{array}{c}\text { proliferation, invasion } \\
\end{array}$ & [39] \\
\hline & exosome & microRNA-23a/b, HIF & tumour growth, chemoresistance, migration, proliferation & [67] \\
\hline & exosome & 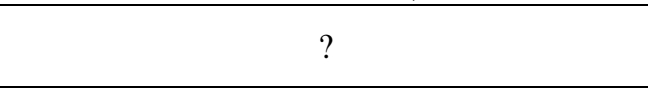 & $\begin{array}{c}\text { tumour growth, angiogenesis macrophage infiltration, proliferation, } \\
\text { migration }\end{array}$ & {$[17]$} \\
\hline \multirow{3}{*}{ Pancreas } & FA & $?$ & migration, invasion, EMT and gemcitabine resistance & [15] \\
\hline & glutamine & $?$ & proliferation & {$[22]$} \\
\hline & ? & ? & migration & [23] \\
\hline \multirow{2}{*}{ Colon } & FA (oleic acid) & metabolism, autophagy, EMT & survival, migration, tumour growth & [72] \\
\hline & $?$ & Akt, mTor & proliferation, migration, invasion & {$[58]$} \\
\hline Gastric & FA (oleic acid) & Akt & invasiveness & [102] \\
\hline Myeloma & adipsin, leptin & autophagy activation and apoptosis reduction & chemoresistance & {$[43]$} \\
\hline Lung & exosome & MMP3, MMP9 & migration, invasion, metastasis & [66] \\
\hline
\end{tabular}

Table 1: Molecular mechanisms involved in the effects of adipocytes on cancer cells. Fatty acid: FA 


\section{References}

1. Dumas, J. F., Brisson, L., Chevalier, S., Maheo, K., Fromont, G., Moussata, D., ... Roger, S. (2017). Metabolic reprogramming in cancer cells, consequences on $\mathrm{pH}$ and tumour progression: Integrated therapeutic perspectives with dietary lipids as adjuvant to anticancer treatment. Semin Cancer Biol, 43, 90-110. https://doi.org/10.1016/j.semcancer.2017.03.004

2. Danhier, P., Banski, P., Payen, V. L., Grasso, D., Ippolito, L., Sonveaux, P., \& Porporato, P. E. (2017). Cancer metabolism in space and time: Beyond the Warburg effect. Biochim Biophys Acta Bioenerg, 1858(8), 556-572. https://doi.org/10.1016/j.bbabio.2017.02.001

3. Luong, Q., Huang, J., \& Lee, K. Y. (2019). Deciphering White Adipose Tissue Heterogeneity. Biology (Basel), 8(2). https://doi.org/10.3390/biology8020023

4. Deng, Y., \& Scherer, P. E. (2010). Adipokines as novel biomarkers and regulators of the metabolic syndrome. Ann NY Acad Sci, 1212, E1-E19. https://doi.org/10.1111/j.1749$6632.2010 .05875 . x$

5. Proenca, A. R., Sertie, R. A., Oliveira, A. C., Campana, A. B., Caminhotto, R. O., Chimin, P., \& Lima, F. B. (2014). New concepts in white adipose tissue physiology. Braz J Med Biol Res, 47(3), 192205.

6. Carter, J. C., \& Church, F. C. (2012). Mature breast adipocytes promote breast cancer cell motility. Exp Mol Pathol, 92(3), 312-7. https://doi.org/10.1016/j.yexmp.2012.03.005

7. Baenke, F., Peck, B., Miess, H., \& Schulze, A. (2013). Hooked on fat: the role of lipid synthesis in cancer metabolism and tumour development. Dis Model Mech, 6(6), 1353-63. https://doi.org/10.1242/dmm.011338

8. Anand, P., Kunnumakkara, A. B., Sundaram, C., Harikumar, K. B., Tharakan, S. T., Lai, O. S., ... Aggarwal, B. B. (2008). Cancer is a preventable disease that requires major lifestyle changes. Pharm Res, 25(9), 2097-116. https://doi.org/10.1007/s11095-008-9661-9 
9. Kern, P. A., Ranganathan, S., Li, C., Wood, L., \& Ranganathan, G. (2001). Adipose tissue tumor necrosis factor and interleukin-6 expression in human obesity and insulin resistance. Am J Physiol Endocrinol Metab, 280(5), E745-51. https://doi.org/10.1152/ajpendo.2001.280.5.E745

10. Booth, A., Magnuson, A., Fouts, J., \& Foster, M. (2015). Adipose tissue, obesity and adipokines: role in cancer promotion. Horm Mol Biol Clin Investig, 21(1), 57-74. https://doi.org/10.1515/hmbci-2014-0037

11. Lee, C. H., Woo, Y. C., Wang, Y., Yeung, C. Y., Xu, A., \& Lam, K. S. (2015). Obesity, adipokines and cancer: an update. Clin Endocrinol (Oxf), 83(2), 147-56. https://doi.org/10.1111/cen.12667

12. Dirat, B., Bochet, L., Dabek, M., Daviaud, D., Dauvillier, S., Majed, B., ... Muller, C. (2011). Cancerassociated adipocytes exhibit an activated phenotype and contribute to breast cancer invasion. Cancer Res, 71(7), 2455-65. https://doi.org/10.1158/0008-5472.CAN-10-3323

13. Nieman, K. M., Kenny, H. A., Penicka, C. V., Ladanyi, A., Buell-Gutbrod, R., Zillhardt, M. R., ... Lengyel, E. (2011). Adipocytes promote ovarian cancer metastasis and provide energy for rapid tumor growth. Nat Med, 17(11), 1498-503. https://doi.org/10.1038/nm.2492

14. Diedrich, J. D., Rajagurubandara, E., Herroon, M. K., Mahapatra, G., Huttemann, M., \& Podgorski, I. (2016). Bone marrow adipocytes promote the Warburg phenotype in metastatic prostate tumors via HIF-1alpha activation. Oncotarget, $7(40), 64854-64877$. https://doi.org/10.18632/oncotarget.11712

15. Okumura, T., Ohuchida, K., Sada, M., Abe, T., Endo, S., Koikawa, K., ... Nakamura, M. (2017). Extra-pancreatic invasion induces lipolytic and fibrotic changes in the adipose microenvironment, with released fatty acids enhancing the invasiveness of pancreatic cancer cells. Oncotarget, 8(11), 18280-18295. https://doi.org/10.18632/oncotarget.15430

16. Hu, W., Ru, Z., Zhou, Y., Xiao, W., Sun, R., Zhang, S., ... Yang, H. (2019). Lung cancer-derived extracellular vesicles induced myotube atrophy and adipocyte lipolysis via the extracellular IL6-mediated STAT3 pathway. Biochim Biophys Acta Mol Cell Biol Lipids, 1864(8), 1091-1102. https://doi.org/10.1016/j.bbalip.2019.04.006 
17. Wang, S., Xu, M., Li, X., Su, X., Xiao, X., Keating, A., \& Zhao, R. C. (2018). Exosomes released by hepatocarcinoma cells endow adipocytes with tumor-promoting properties. J Hematol Oncol, 11(1), 82. https://doi.org/10.1186/s13045-018-0625-1

18. Sheng, X., Tucci, J., Parmentier, J. H., Ji, L., Behan, J. W., Heisterkamp, N., \& Mittelman, S. D. (2016). Adipocytes cause leukemia cell resistance to daunorubicin via oxidative stress response. Oncotarget, 7(45), 73147-73159. https://doi.org/10.18632/oncotarget.12246

19. Wang, F., Gao, S., Chen, F., Fu, Z., Yin, H., Lu, X., ... Lu, C. (2014). Mammary fat of breast cancer: gene expression profiling and functional characterization. PLoS One, 9(10), e109742. https://doi.org/10.1371/journal.pone.0109742

20. Wu, Q., Li, J., Li, Z., Sun, S., Zhu, S., Wang, L., ... Wang, C. (2019). Exosomes from the tumouradipocyte interplay stimulate beige/brown differentiation and reprogram metabolism in stromal adipocytes to promote tumour progression. Journal of Experimental \& Clinical Cancer Research : CR, 38. https://doi.org/10.1186/s13046-019-1210-3

21. Wu, Q., Sun, S., Li, Z., Yang, Q., Li, B., Zhu, S., ... Sun, S. (2018). Tumour-originated exosomal miR155 triggers cancer-associated cachexia to promote tumour progression. Mol Cancer, 17(1), 155. https://doi.org/10.1186/s12943-018-0899-5

22. Meyer, K. A., Neeley, C. K., Baker, N. A., Washabaugh, A. R., Flesher, C. G., Nelson, B. S., ... O'Rourke, R. W. (2016). Adipocytes promote pancreatic cancer cell proliferation via glutamine transfer. Biochem Biophys Rep, 7, 144-149. https://doi.org/10.1016/j.bbrep.2016.06.004

23. Cai, Z., Liang, Y., Xing, C., Wang, H., Hu, P., Li, J., ... Jiang, C. (2019). Cancerassociated adipocytes exhibit distinct phenotypes and facilitate tumor progression in pancreatic cancer. Oncol Rep, 42(6), 2537-2549. https://doi.org/10.3892/or.2019.7365

24. Ye, H., Adane, B., Khan, N., Sullivan, T., Minhajuddin, M., Gasparetto, M., ... Jordan, C. T. (2016). Leukemic Stem Cells Evade Chemotherapy by Metabolic Adaptation to an Adipose Tissue Niche. Cell Stem Cell, 19(1), 23-37. https://doi.org/10.1016/j.stem.2016.06.001 
25. Shafat, M. S., Oellerich, T., Mohr, S., Robinson, S. D., Edwards, D. R., Marlein, C. R., ... Rushworth, S. A. (2017). Leukemic blasts program bone marrow adipocytes to generate a protumoral microenvironment. Blood, 129(10), 1320-1332. https://doi.org/10.1182/blood-2016-08734798

26. Attane, C., Esteve, D., Chaoui, K., lacovoni, J. S., Corre, J., Moutahir, M., ... Muller, C. (2020). Human Bone Marrow Is Comprised of Adipocytes with Specific Lipid Metabolism. Cell Rep, 30(4), 949-958 e6. https://doi.org/10.1016/j.celrep.2019.12.089

27. Bochet, L., Lehuede, C., Dauvillier, S., Wang, Y. Y., Dirat, B., Laurent, V., ... Muller, C. (2013). Adipocyte-derived fibroblasts promote tumor progression and contribute to the desmoplastic reaction in breast cancer. Cancer Res, 73(18), 5657-68. https://doi.org/10.1158/00085472.CAN-13-0530

28. Lu, W., Wan, Y., Li, Z., Zhu, B., Yin, C., Liu, H., ... Shi, J. (2018). Growth differentiation factor 15 contributes to marrow adipocyte remodeling in response to the growth of leukemic cells. J Exp Clin Cancer Res, 37(1), 66. https://doi.org/10.1186/s13046-018-0738-y

29. Herroon, M. K., Diedrich, J. D., Rajagurubandara, E., Martin, C., Maddipati, K. R., Kim, S., ... Podgorski, I. (2019). Prostate Tumor Cell-Derived IL1beta Induces an Inflammatory Phenotype in Bone Marrow Adipocytes and Reduces Sensitivity to Docetaxel via Lipolysis-Dependent Mechanisms. Mol Cancer Res, 17(12), 2508-2521. https://doi.org/10.1158/1541-7786.MCR-190540

30. Santander, A. M., Lopez-Ocejo, O., Casas, O., Agostini, T., Sanchez, L., Lamas-Basulto, E., ... Torroella-Kouri, M. (2015). Paracrine Interactions between Adipocytes and Tumor Cells Recruit and Modify Macrophages to the Mammary Tumor Microenvironment: The Role of Obesity and Inflammation in Breast Adipose Tissue. Cancers (Basel), 7(1), 143-78. https://doi.org/10.3390/cancers7010143

31. Arendt, L. M., McCready, J., Keller, P. J., Baker, D. D., Naber, S. P., Seewaldt, V., \& Kuperwasser, C. (2013). Obesity promotes breast cancer by CCL2-mediated macrophage recruitment and 
angiogenesis. Cancer Research, 73(19), 6080-6093. https://doi.org/10.1158/0008-5472.CAN13-0926

32. Xu, L., Shen, M., Chen, X., Zhu, R., Yang, D. R., Tsai, Y., ... Lee, S. O. (2018). Adipocytes affect castration-resistant prostate cancer cells to develop the resistance to cytotoxic action of NK cells with alterations of PD-L1/NKG2D ligand levels in tumor cells. Prostate, 78(5), 353-364. https://doi.org/10.1002/pros.23479

33. Duong, M. N., Cleret, A., Matera, E. L., Chettab, K., Mathe, D., Valsesia-Wittmann, S., ... Dumontet, C. (2015). Adipose cells promote resistance of breast cancer cells to trastuzumabmediated antibody-dependent cellular cytotoxicity. Breast Cancer Res, 17, 57. https://doi.org/10.1186/s13058-015-0569-0

34. Incio, J., Ligibel, J. A., McManus, D. T., Suboj, P., Jung, K., Kawaguchi, K., ... Jain, R. K. (2018). Obesity promotes resistance to anti-VEGF therapy in breast cancer by up-regulating IL- 6 and potentially FGF-2. Science Translational Medicine, 10(432), eaag0945. https://doi.org/10.1126/scitranslmed.aag0945

35. Iwamoto, H., Abe, M., Yang, Y., Cui, D., Seki, T., Nakamura, M., ... Cao, Y. (2018). Cancer Lipid Metabolism Confers Antiangiogenic Drug Resistance. Cell Metabolism, 28(1), 104-117.e5. https://doi.org/10.1016/j.cmet.2018.05.005

36. Caers, J., Deleu, S., Belaid, Z., De Raeve, H., Van Valckenborgh, E., De Bruyne, E., ... Vanderkerken, K. (2007). Neighboring adipocytes participate in the bone marrow microenvironment of multiple myeloma cells. Leukemia, 21(7), 1580-4. https://doi.org/10.1038/sj.leu.2404658

37. Onuma, M., Bub, J. D., Rummel, T. L., \& Iwamoto, Y. (2003). Prostate cancer cell-adipocyte interaction: leptin mediates androgen-independent prostate cancer cell proliferation through c-Jun NH2-terminal kinase. J Biol Chem, 278(43), 42660-7. https://doi.org/10.1074/jbc.M304984200 
38. Sharma, D., Wang, J., Fu, P. P., Sharma, S., Nagalingam, A., Mells, J., ... Saxena, N. K. (2010). Adiponectin antagonizes the oncogenic actions of leptin in hepatocellular carcinogenesis. Hepatology, 52(5), 1713-22. https://doi.org/10.1002/hep.23892

39. Stefanou, N., Papanikolaou, V., Furukawa, Y., Nakamura, Y., \& Tsezou, A. (2010). Leptin as a critical regulator of hepatocellular carcinoma development through modulation of human telomerase reverse transcriptase. BMC Cancer, 10, 442. https://doi.org/10.1186/1471-2407$10-442$

40. Strong, A. L., Ohlstein, J. F., Biagas, B. A., Rhodes, L. V., Pei, D. T., Tucker, H. A., ... Bunnell, B. A. (2015). Leptin produced by obese adipose stromal/stem cells enhances proliferation and metastasis of estrogen receptor positive breast cancers. Breast Cancer Res, 17, 112. https://doi.org/10.1186/s13058-015-0622-z

41. Park, J., Kusminski, C. M., Chua, S. C., \& Scherer, P. E. (2010). Leptin receptor signaling supports cancer cell metabolism through suppression of mitochondrial respiration in vivo. Am J Pathol, 177(6), 3133-44. https://doi.org/10.2353/ajpath.2010.100595

42. Chi, M., Chen, J., Ye, Y., Tseng, H. Y., Lai, F., Tay, K. H., ... Zhang, X. D. (2014). Adipocytes contribute to resistance of human melanoma cells to chemotherapy and targeted therapy. Curr Med Chem, 21(10), 1255-67.

43. Liu, Z., Xu, J., He, J., Liu, H., Lin, P., Wan, X., ... Yang, J. (2015). Mature adipocytes in bone marrow protect myeloma cells against chemotherapy through autophagy activation. Oncotarget, 6(33), 34329-41. https://doi.org/10.18632/oncotarget.6020

44. Grossmann, M. E., Ray, A., Dogan, S., Mizuno, N. K., \& Cleary, M. P. (2008). Balance of adiponectin and leptin modulates breast cancer cell growth. Cell Res, 18(11), 1154-6. https://doi.org/10.1038/cr.2008.293

45. An, W., Bai, Y., Deng, S. X., Gao, J., Ben, Q. W., Cai, Q. C., ... Li, Z. S. (2012). Adiponectin levels in patients with colorectal cancer and adenoma: a meta-analysis. Eur J Cancer Prev, 21(2), 12633. https://doi.org/10.1097/CEJ.0b013e32834c9b55 
46. Saxena, A., Chumanevich, A., Fletcher, E., Larsen, B., Lattwein, K., Kaur, K., \& Fayad, R. (2012). Adiponectin deficiency: role in chronic inflammation induced colon cancer. Biochim Biophys Acta, 1822(4), 527-36. https://doi.org/10.1016/j.bbadis.2011.12.006

47. Saxena, N. K., Fu, P. P., Nagalingam, A., Wang, J., Handy, J., Cohen, C., ... Anania, F. A. (2010). Adiponectin modulates $\mathrm{C}$-jun $\mathrm{N}$-terminal kinase and mammalian target of rapamycin and inhibits hepatocellular carcinoma. Gastroenterology, 139(5), 1762-73, 1773 e1-5. https://doi.org/10.1053/j.gastro.2010.07.001

48. Karaduman, M., Bilici, A., Ozet, A., Sengul, A., Musabak, U., \& Alomeroglu, M. (2007). Tissue levels of adiponectin in breast cancer patients. Med Oncol, 24(4), 361-6. https://doi.org/10.1007/s12032-007-0021-0

49. Falk Libby, E., Liu, J., Li, Y. I., Lewis, M. J., Demark-Wahnefried, W., \& Hurst, D. R. (2016). Globular adiponectin enhances invasion in human breast cancer cells. Oncol Lett, 11(1), 633-641. https://doi.org/10.3892/ol.2015.3965

50. Fujisaki, K., Fujimoto, H., Sangai, T., Nagashima, T., Sakakibara, M., Shiina, N., ... Miyazaki, M. (2015). Cancer-mediated adipose reversion promotes cancer cell migration via IL-6 and MCP-1. Breast Cancer Res Treat, 150(2), 255-63. https://doi.org/10.1007/s10549-015-3318-2

51. Cardenas, C., Montagna, M. K., Pitruzzello, M., Lima, E., Mor, G., \& Alvero, A. B. (2017). Adipocyte microenvironment promotes Bclxl expression and confers chemoresistance in ovarian cancer cells. Apoptosis, 22(4), 558-569. https://doi.org/10.1007/s10495-016-1339-x

52. He, J. Y., Wei, X. H., Li, S. J., Liu, Y., Hu, H. L., Li, Z. Z., ... Sun, L. (2018). Adipocyte-derived IL-6 and leptin promote breast Cancer metastasis via upregulation of Lysyl Hydroxylase-2 expression. Cell Commun Signal, 16(1), 100. https://doi.org/10.1186/s12964-018-0309-z

53. Bochet, L., Meulle, A., Imbert, S., Salles, B., Valet, P., \& Muller, C. (2011). Cancer-associated adipocytes promotes breast tumor radioresistance. Biochem Biophys Res Commun, 411(1), 102-6. https://doi.org/10.1016/j.bbrc.2011.06.101 
54. Wang, C. H., Wang, P. J., Hsieh, Y. C., Lo, S., Lee, Y. C., Chen, Y. C., ... Yuan, S. S. (2018). Resistin facilitates breast cancer progression via TLR4-mediated induction of mesenchymal phenotypes and stemness properties. Oncogene, 37(5), 589-600. https://doi.org/10.1038/onc.2017.357

55. Goto, H., Shimono, Y., Funakoshi, Y., Imamura, Y., Toyoda, M., Kiyota, N., ... Minami, H. (2019). Adipose-derived stem cells enhance human breast cancer growth and cancer stem cell-like properties through adipsin. Oncogene, 38(6), 767-779. https://doi.org/10.1038/s41388-018$0477-8$

56. Drew, B. G., Hamidi, H., Zhou, Z., Villanueva, C. J., Krum, S. A., Calkin, A. C., ... Hevener, A. L. (2015). Estrogen receptor (ER)alpha-regulated lipocalin 2 expression in adipose tissue links obesity with breast cancer progression. I Biol Chem, 290(9), 5566-81. https://doi.org/10.1074/jbc.M114.606459

57. Wang, C., Gao, C., Meng, K., Qiao, H., \& Wang, Y. (2015). Human adipocytes stimulate invasion of breast cancer MCF-7 cells by secreting IGFBP-2. PLoS One, 10(3), e0119348. https://doi.org/10.1371/journal.pone.0119348

58. Ko, J. H., Um, J. Y., Lee, S. G., Yang, W. M., Sethi, G., \& Ahn, K. S. (2019). Conditioned media from adipocytes promote proliferation, migration, and invasion in melanoma and colorectal cancer cells. J Cell Physiol, 234(10), 18249-18261. https://doi.org/10.1002/jcp.28456

59. Huang, J., Duran, A., Reina-Campos, M., Valencia, T., Castilla, E. A., Muller, T. D., ... Diaz-Meco, M. T. (2018). Adipocyte p62/SQSTM1 Suppresses Tumorigenesis through Opposite Regulations of Metabolism in Adipose Tissue and Tumor. Cancer Cell, 33(4), 770-784 e6. https://doi.org/10.1016/j.ccell.2018.03.001

60. Griner, S. E., Wang, K. J., Joshi, J. P., \& Nahta, R. (2013). Mechanisms of Adipocytokine-Mediated Trastuzumab Resistance in HER2-Positive Breast Cancer Cell Lines. Curr Pharmacogenomics Person Med, 11(1), 31-41. https://doi.org/10.2174/1875692111311010006 
61. Pramanik, R., Sheng, X., Ichihara, B., Heisterkamp, N., \& Mittelman, S. D. (2013). Adipose tissue attracts and protects acute lymphoblastic leukemia cells from chemotherapy. Leuk Res, 37(5), 503-9. https://doi.org/10.1016/j.leukres.2012.12.013

62. Ehsanipour, E. A., Sheng, X., Behan, J. W., Wang, X., Butturini, A., Avramis, V. I., \& Mittelman, S. D. (2013). Adipocytes cause leukemia cell resistance to L-asparaginase via release of glutamine. Cancer Res, 73(10), 2998-3006. https://doi.org/10.1158/0008-5472.CAN-12-4402

63. Huang, C. K., Chang, P. H., Kuo, W. H., Chen, C. L., Jeng, Y. M., Chang, K. J., ... Lee, W. H. (2017). Adipocytes promote malignant growth of breast tumours with monocarboxylate transporter 2 expression via beta-hydroxybutyrate. Nat Commun, 8, 14706. https://doi.org/10.1038/ncomms14706

64. Clement, E., Lazar, I., Attane, C., Carrie, L., Dauvillier, S., Ducoux-Petit, M., ... Nieto, L. (2020). Adipocyte extracellular vesicles carry enzymes and fatty acids that stimulate mitochondrial metabolism and remodeling in tumor cells. EMBO J, 39(3), e102525. https://doi.org/10.15252/embj.2019102525

65. Lazar, I., Clement, E., Dauvillier, S., Milhas, D., Ducoux-Petit, M., LeGonidec, S., ... Nieto, L. (2016). Adipocyte Exosomes Promote Melanoma Aggressiveness through Fatty Acid Oxidation: A Novel Mechanism Linking Obesity and Cancer. Cancer Res, 76(14), 4051-7. https://doi.org/10.1158/0008-5472.CAN-16-0651

66. Wang, J., Wu, Y., Guo, J., Fei, X., Yu, L., \& Ma, S. (2017). Adipocyte-derived exosomes promote lung cancer metastasis by increasing MMP9 activity via transferring MMP3 to lung cancer cells. Oncotarget, 8(47), 81880-81891. https://doi.org/10.18632/oncotarget.18737

67. Liu, Y., Tan, J., Ou, S., Chen, J., \& Chen, L. (2019). Adipose-derived exosomes deliver miR-23a/b to regulate tumor growth in hepatocellular cancer by targeting the VHL/HIF axis. J Physiol Biochem, 75(3), 391-401. https://doi.org/10.1007/s13105-019-00692-6 
68. Au Yeung, C. L., Co, N. N., Tsuruga, T., Yeung, T. L., Kwan, S. Y., Leung, C. S., ... Mok, S. C. (2016). Exosomal transfer of stroma-derived miR21 confers paclitaxel resistance in ovarian cancer cells through targeting APAF1. Nat Commun, 7, 11150. https://doi.org/10.1038/ncomms11150

69. Wang, Y. Y., Attane, C., Milhas, D., Dirat, B., Dauvillier, S., Guerard, A., ... Muller, C. (2017). Mammary adipocytes stimulate breast cancer invasion through metabolic remodeling of tumor cells. JCI Insight, 2(4), e87489. https://doi.org/10.1172/jci.insight.87489

70. Laurent, V., Toulet, A., Attane, C., Milhas, D., Dauvillier, S., Zaidi, F., ... Muller, C. (2019). Periprostatic Adipose Tissue Favors Prostate Cancer Cell Invasion in an Obesity-Dependent Manner: Role of Oxidative Stress. Mol Cancer Res, 17(3), 821-835. https://doi.org/10.1158/1541-7786.MCR-18-0748

71. Kwan, H. Y., Fu, X., Liu, B., Chao, X., Chan, C. L., Cao, H., ... Yu, Z. L. (2014). Subcutaneous adipocytes promote melanoma cell growth by activating the Akt signaling pathway: role of palmitic acid. J Biol Chem, 289(44), 30525-37. https://doi.org/10.1074/jbc.M114.593210

72. Wen, Y. A., Xing, X., Harris, J. W., Zaytseva, Y. Y., Mitov, M. I., Napier, D. L., ... Gao, T. (2017). Adipocytes activate mitochondrial fatty acid oxidation and autophagy to promote tumor growth in colon cancer. Cell Death Dis, 8(2), e2593. https://doi.org/10.1038/cddis.2017.21

73. Gazi, E., Gardner, P., Lockyer, N. P., Hart, C. A., Brown, M. D., \& Clarke, N. W. (2007). Direct evidence of lipid translocation between adipocytes and prostate cancer cells with imaging FTIR microspectroscopy. J Lipid Res, 48(8), 1846-56. https://doi.org/10.1194/jlr.M700131-JLR200

74. Zhang, M., Di Martino, J. S., Bowman, R. L., Campbell, N. R., Baksh, S. C., Simon-Vermot, T., ... White, R. M. (2018). Adipocyte-Derived Lipids Mediate Melanoma Progression via FATP Proteins. Cancer Discov, 8(8), 1006-1025. https://doi.org/10.1158/2159-8290.CD-17-1371

75. Petan, T., Jarc, E., \& Jusovic, M. (2018). Lipid Droplets in Cancer: Guardians of Fat in a Stressful World. Molecules, 23(8). https://doi.org/10.3390/molecules23081941 
76. Bensaad, K., Favaro, E., Lewis, C. A., Peck, B., Lord, S., Collins, J. M., ... Harris, A. L. (2014). Fatty acid uptake and lipid storage induced by HIF-1alpha contribute to cell growth and survival after hypoxia-reoxygenation. Cell Rep, 9(1), 349-365. https://doi.org/10.1016/j.celrep.2014.08.056

77. Qu, Q., Zeng, F., Liu, X., Wang, Q. J., \& Deng, F. (2016). Fatty acid oxidation and carnitine palmitoyltransferase I: emerging therapeutic targets in cancer. Cell Death Dis, 7, e2226. https://doi.org/10.1038/cddis.2016.132

78. Yang, D., Li, Y., Xing, L., Tan, Y., Sun, J., Zeng, B., ... Wang, Y. (2018). Utilization of adipocytederived lipids and enhanced intracellular trafficking of fatty acids contribute to breast cancer progression. Cell Commun Signal, 16(1), 32. https://doi.org/10.1186/s12964-018-0221-6

79. Balaban, S., Shearer, R. F., Lee, L. S., van Geldermalsen, M., Schreuder, M., Shtein, H. C., ... Hoy, A. J. (2017). Adipocyte lipolysis links obesity to breast cancer growth: adipocyte-derived fatty acids drive breast cancer cell proliferation and migration. Cancer Metab, 5, 1. https://doi.org/10.1186/s40170-016-0163-7

80. Luis, C., Duarte, F., Faria, I., Jarak, I., Oliveira, P. F., Alves, M. G., ... Fernandes, R. (2019). Warburg Effect Inversion: Adiposity shifts central primary metabolism in MCF-7 breast cancer cells. Life Sci, 223, 38-46. https://doi.org/10.1016/j.Ifs.2019.03.016

81. Miranda, F., Mannion, D., Liu, S., Zheng, Y., Mangala, L. S., Redondo, C., ... Ahmed, A. A. (2016). Salt-Inducible Kinase 2 Couples Ovarian Cancer Cell Metabolism with Survival at the AdipocyteRich Metastatic Niche. Cancer Cell, 30(2), 273-289. https://doi.org/10.1016/j.ccell.2016.06.020

82. Tabe, Y., Yamamoto, S., Saitoh, K., Sekihara, K., Monma, N., Ikeo, K., ... Andreeff, M. (2017). Bone Marrow Adipocytes Facilitate Fatty Acid Oxidation Activating AMPK and a Transcriptional Network Supporting Survival of Acute Monocytic Leukemia Cells. Cancer Res, 77(6), 1453-1464. https://doi.org/10.1158/0008-5472.CAN-16-1645

83. Samudio, I., Fiegl, M., \& Andreeff, M. (2009). Mitochondrial Uncoupling and the Warburg Effect: Molecular Basis for the Reprogramming of Cancer Cell Metabolism. Cancer Research, 69(6), 2163-2166. https://doi.org/10.1158/0008-5472.CAN-08-3722 
84. Behan, J. W., Yun, J. P., Proektor, M. P., Ehsanipour, E. A., Arutyunyan, A., Moses, A. S., ... Mittelman, S. D. (2009). Adipocytes impair leukemia treatment in mice. Cancer Res, 69(19), 7867-74. https://doi.org/10.1158/0008-5472.CAN-09-0800

85. Schönfeld, P., \& Wojtczak, L. (2008). Fatty acids as modulators of the cellular production of reactive oxygen species. Free Radical Biology and Medicine, 45(3), 231-241. https://doi.org/10.1016/j.freeradbiomed.2008.04.029

86. Li, S., Wu, T., Lu, Y.-X., Wang, J.-X., Yu, F.-H., Yang, M.-Z., ... Tian, T. (2020). Obesity promotes gastric cancer metastasis via diacylglycerol acyltransferase 2-dependent lipid droplets accumulation and redox homeostasis. Redox Biology, 36, 101596. https://doi.org/10.1016/j.redox.2020.101596

87. Mukherjee, A., Chiang, C. Y., Daifotis, H. A., Nieman, K. M., Fahrmann, J. F., Lastra, R. R., ... Lengyel, E. (2020). Adipocyte-Induced FABP4 Expression in Ovarian Cancer Cells Promotes Metastasis and Mediates Carboplatin Resistance. Cancer Res, 80(8), 1748-1761. https://doi.org/10.1158/0008-5472.CAN-19-1999

88. Herroon, M. K., Rajagurubandara, E., Diedrich, J. D., Heath, E. I., \& Podgorski, I. (2018). Adipocyte-activated oxidative and ER stress pathways promote tumor survival in bone via upregulation of Heme Oxygenase 1 and Survivin. Sci Rep, 8(1), 40. https://doi.org/10.1038/s41598-017-17800-5

89. Balaban, S., Lee, L. S., Schreuder, M., \& Hoy, A. J. (2015). Obesity and cancer progression: is there a role of fatty acid metabolism? Biomed Res Int, 2015, 274585. https://doi.org/10.1155/2015/274585

90. Gharpure, K. M., Pradeep, S., Sans, M., Rupaimoole, R., Ivan, C., Wu, S. Y., ... Sood, A. K. (2018). FABP4 as a key determinant of metastatic potential of ovarian cancer. Nat Commun, 9(1), 2923. https://doi.org/10.1038/s41467-018-04987-y 
91. Ladanyi, A., Mukherjee, A., Kenny, H. A., Johnson, A., Mitra, A. K., Sundaresan, S., ... Lengyel, E. (2018). Adipocyte-induced CD36 expression drives ovarian cancer progression and metastasis. Oncogene, 37(17), 2285-2301. https://doi.org/10.1038/s41388-017-0093-z

92. Pascual, G., Avgustinova, A., Mejetta, S., Martin, M., Castellanos, A., Attolini, C. S., ... Benitah, S. A. (2017). Targeting metastasis-initiating cells through the fatty acid receptor CD36. Nature, 541(7635), 41-45. https://doi.org/10.1038/nature20791

93. Zaoui, M., Morel, M., Ferrand, N., Fellahi, S., Bastard, J. P., Lamaziere, A., ... Sabbah, M. (2019). Breast-Associated Adipocytes Secretome Induce Fatty Acid Uptake and Invasiveness in Breast Cancer Cells via CD36 Independently of Body Mass Index, Menopausal Status and Mammary Density. Cancers (Basel), 11(12). https://doi.org/10.3390/cancers11122012

94. Hao, J., Zhang, Y., Yan, X., Yan, F., Sun, Y., Zeng, J., ... Li, B. (2018). Circulating Adipose Fatty Acid Binding Protein Is a New Link Underlying Obesity-Associated Breast/Mammary Tumor Development. Cell Metab, 28(5), 689-705 e5. https://doi.org/10.1016/j.cmet.2018.07.006

95. Yan, F., Shen, N., Pang, J. X., Zhang, Y. W., Rao, E. Y., Bode, A. M., ... Liu, S. J. (2017). Fatty acidbinding protein FABP4 mechanistically links obesity with aggressive AML by enhancing aberrant DNA methylation in AML cells. Leukemia, 31(6), 1434-1442. https://doi.org/10.1038/leu.2016.349

96. Kim, Y. S., Jung, J., Jeong, H., Lee, J. H., Oh, H. E., Lee, E. S., \& Choi, J. W. (2019). High Membranous Expression of Fatty Acid Transport Protein 4 Is Associated with Tumorigenesis and Tumor Progression in Clear Cell Renal Cell Carcinoma. Dis Markers, 2019, 5702026. https://doi.org/10.1155/2019/5702026

97. Mollinedo, F., \& Gajate, C. (2014). Lipid rafts as major platforms for signaling regulation in cancer. Adv. Biol. Regul. https://doi.org/S2212-4926(14)00058-X [pii];10.1016/j.jbior.2014.10.003 [doi]

98. Hilvo, M., Denkert, C., Lehtinen, L., Muller, B., Brockmoller, S., Seppanen-Laakso, T., ... Oresic, M. (2011). Novel theranostic opportunities offered by characterization of altered membrane 
lipid metabolism in breast cancer progression. Cancer Res, 71(9), 3236-45. https://doi.org/10.1158/0008-5472.CAN-10-3894

99. Giudetti, A. M., De Domenico, S., Ragusa, A., Lunetti, P., Gaballo, A., Franck, J., ... Vergara, D. (2019). A specific lipid metabolic profile is associated with the epithelial mesenchymal transition program. Biochim Biophys Acta Mol Cell Biol Lipids, 1864(3), 344-357. https://doi.org/10.1016/j.bbalip.2018.12.011

100. Igal, R. A. (2016). Stearoyl CoA desaturase-1: New insights into a central regulator of cancer metabolism. Biochim Biophys Acta, 1861(12 Pt A), 1865-1880. https://doi.org/10.1016/j.bbalip.2016.09.009

101. Watt, M. J., Clark, A. K., Selth, L. A., Haynes, V. R., Lister, N., Rebello, R., ... Taylor, R. A. (2019). Suppressing fatty acid uptake has therapeutic effects in preclinical models of prostate cancer. Sci Transl Med, 11(478). https://doi.org/10.1126/scitranslmed.aau5758

102. Xiang, F., Wu, K., Liu, Y., Shi, L., Wang, D., Li, G., ... Wang, G. (2017). Omental adipocytes enhance the invasiveness of gastric cancer cells by oleic acid-induced activation of the PI3K-Akt signaling pathway. Int J Biochem Cell Biol, 84, 14-21. https://doi.org/10.1016/j.biocel.2016.12.002

103. Yang, J., Zaman, M. M., Vlasakov, I., Roy, R., Huang, L., Martin, C. R., ... Moses, M. A. (2019). Adipocytes promote ovarian cancer chemoresistance. Sci Rep, 9(1), 13316. https://doi.org/10.1038/s41598-019-49649-1

104. Volden, P. A., Skor, M. N., Johnson, M. B., Singh, P., Patel, F. N., McClintock, M. K., ... Conzen, S. D. (2016). Mammary Adipose Tissue-Derived Lysophospholipids Promote Estrogen ReceptorNegative Mammary Epithelial Cell Proliferation. Cancer Prev Res (Phila), 9(5), 367-78. https://doi.org/10.1158/1940-6207.CAPR-15-0107

105. Bougnoux, P., Giraudeau, B., \& Couet, C. (2006). Diet, cancer, and the lipidome. Cancer Epidemiol Biomarkers Prev, 15(3), 416-21. https://doi.org/10.1158/1055-9965.EPI-05-0546

106. Figiel, S., Pinault, M., Domingo, I., Guimaraes, C., Guibon, R., Besson, P., ... Fromont, G. (2018). Fatty acid profile in peri-prostatic adipose tissue and prostate cancer aggressiveness in African- 
Caribbean and Caucasian patients. Eur J Cancer, 91, 107-115. https://doi.org/10.1016/j.ejca.2017.12.017

107. Ouldamer, L., Goupille, C., Vilde, A., Arbion, F., Body, G., Chevalier, S., ... Bougnoux, P. (2016). N-3 Polyunsaturated Fatty Acids of Marine Origin and Multifocality in Human Breast Cancer. PLoS One, 11(1), e0147148. https://doi.org/10.1371/journal.pone.0147148

108. Figiel, S., Bery, F., Chantome, A., Fontaine, D., Pasqualin, C., Maupoil, V., ... Maheo, K. (2019). A Novel Calcium-Mediated EMT Pathway Controlled by Lipids: An Opportunity for Prostate Cancer Adjuvant Therapy. Cancers (Basel), 11(11). https://doi.org/10.3390/cancers11111814

109. Herroon, M. K., Diedrich, J. D., \& Podgorski, I. (2016). New 3D-Culture Approaches to Study Interactions of Bone Marrow Adipocytes with Metastatic Prostate Cancer Cells. Front Endocrinol (Lausanne), 7, 84. https://doi.org/10.3389/fendo.2016.00084

110. Delort, L., Lequeux, C., Dubois, V., Dubouloz, A., Billard, H., Mojallal, A., ... Caldefie-Chezet, F. (2013). Reciprocal interactions between breast tumor and its adipose microenvironment based on a 3D adipose equivalent model. PLoS One, 8(6), e66284. https://doi.org/10.1371/journal.pone.0066284

111. Muller, S., Ader, I., Creff, J., Lemenager, H., Achard, P., Casteilla, L., ... Deschaseaux, F. (2019). Human adipose stromal-vascular fraction self-organizes to form vascularized adipose tissue in 3D cultures. Sci Rep, 9(1), 7250. https://doi.org/10.1038/s41598-019-43624-6

112. Kaneko, A., Satoh, Y., Tokuda, Y., Fujiyama, C., Udo, K., \& Uozumi, J. (2010). Effects of adipocytes on the proliferation and differentiation of prostate cancer cells in a 3-D culture model. Int J Urol, 17(4), 369-76. https://doi.org/10.1111/j.1442-2042.2010.02472.x

113. Roman, M., Wrobel, T. P., Panek, A., Paluszkiewicz, C., \& Kwiatek, W. M. (2020). Lipid droplets in prostate cancer cells and effect of irradiation studied by Raman microspectroscopy. Biochimica et Biophysica Acta (BBA) - Molecular and Cell Biology of Lipids, 1865(9), 158753. https://doi.org/10.1016/j.bbalip.2020.158753 
114. Cahu, X., Calvo, J., Poglio, S., Prade, N., Colsch, B., Arcangeli, M. L., ... Pflumio, F. (2017). Bone marrow sites differently imprint dormancy and chemoresistance to T-cell acute lymphoblastic leukemia. Blood Adv, 1(20), 1760-1772. https://doi.org/10.1182/bloodadvances.2017004960 